\title{
A DISTRIBUIÇÃO REALIZADA PELA CAMPANHA DE POPULARIZAÇÃO DO TEATRO E DA DANÇA DE BELO HORIZONTE OU "A GALINHA DOS OVOS DE OURO DA CENA TEATRAL" 1
}

Recebido em: $13 / 01 / 2015$

Aceito em: 22/08/2015

Nádia Bueno Rezende ${ }^{2}$

Universidade Federal de Minas Gerais

Belo Horizonte - MG - Brasil

RESUMO: Há 41 anos a Campanha de Popularização do Teatro e da Dança (CPTD) está inserida no calendário de Belo Horizonte. Partindo de um eixo que considera a produção, a distribuição e o consumo da arte, neste artigo analiso a centralidade das ações da CPTD na distribuição. Pretendo entender a suposta popularização levada a cabo pela CPDT a partir de suas estratégias de distribuição. Utilizo a metodologia historiográfica, tendo como fontes os Relatórios Gerais das edições da CPTD. O presente estudo conclui que pode-se entender as ações de distribuição da CPTD divididas em três eixos: (1) criando formas de facilitar o acesso, tanto no que diz respeito aos preços, quanto aos deslocamentos; (2) promovendo uma intensa divulgação nos meios de comunicação em massa, divulgação essa que tem pretensões de atrair tanto público quanto patrocinadores, e; (3) estabelecendo relações de tradição que geram vínculos com a população e com a cidade.

PALAVRAS CHAVE: Cultura. Atividades de Lazer.

\section{THE DISTRIBUTION MADE BY THE CAMPANHA DE POPULARIZAÇÃO DO TEATRO E DA DANÇA IN BELO HORIZONTE}

ABSTRACT: For 41 years the "Campanha de Popularização do Teatro e da Dança (CPTD)" (Campaign for the popularization of theater and dance) has been a part of Belo Horizonte's cultural calendar. Beginning from a viewpoint that considers production, distribution, and the consumption of art, I analyze, in this text, the importance and centralization of CPTD actions to divulge the aforementioned arts. I aim to understand the intended "popularization" that this campaign promotes starting from its strategies of divulgence . For this research, I have used the historiographic-methodology, in which I used reports from previous editions of this campaign. This paper concluded that it is

\footnotetext{
${ }^{1}$ Acervo do Sinparc - MG. Relatório Final da 33 ${ }^{\text {a }}$ CPTD. Expressão utilizada em reportagem do jornal Hoje em Dia, de 4 de janeiro de 2007. Artigo denominado "Recomeça a Festa do Teatro e da Dança". O presente trabalho é parte da Dissertação de Mestrado da autora, sob orientação do Prof. Doutor Victor Andrade de Melo. Apoio: CAPES; PPGIEL-UFMG.

2 Mestre pelo Programa de Pós-Graduação Interdisciplinar em Estudos do Lazer (PPGIEL - UFMG). Professora da Rede Municipal de Ensino de Belo Horizonte.
} 
possible to understand the actions of distribution of the CPTD as separated into three axes (1) creating ways of facilitating access, both about prices and transportation; (2) promoting an intense marketing scheme, using mass media distribution, which intends to attract the public and sponsors and (3) establishing long-term connections that should create networks with the populus and the city.

KEYWORDS: Culture. Leisure Activities.

Há 41 anos a Campanha de Popularização do Teatro e da Dança (CPTD) está inserida no calendário da cidade de Belo Horizonte. Anualmente ela acontece nos meses de janeiro, fevereiro e março. Trata-se de uma proposta em que vários espetáculos são apresentados em muitos teatros espalhados pela cidade, contemplando exclusivamente as produções artísticas mineiras.

O presente artigo é um recorte da minha dissertação de mestrado, sobre orientação do Professor Doutor Victor Andrade de Melo, que teve como objeto de estudo a CPTD de Belo Horizonte. Partindo de um eixo que considera a produção, a distribuição e o consumo da arte, neste artigo foco a análise na centralidade das ações da CPTD na distribuição. Pretendo entender a suposta popularização levada a cabo pela CPDT a partir de suas estratégias de distribuição.

Para tanto, utilizo a metodologia historiográfica. Uma pesquisa histórica é caracterizada pela localização do objeto de estudos no tempo. Esse tempo não precisa estar em um passado distante ou morto. Também é possível inserir no fluxo temporal um objeto de estudos recente, e esse é o desafio da história do tempo presente.

As fontes - ou evidências, como sugere Thompson (1981) - dessa pesquisa foram coletadas no acervo e no site do Sinparc: são os Relatórios Gerais das edições da CPTD, produzidos pela própria instituição, que contemplam recortes de jornais e documentos que contém referência aos números levantados em cada edição. A CPTD, assim como as instituições em geral, tem preocupações de ordem memorial. A memória 
guarda estreita relação com a identidade, com o sentimento de pertencimento ou não a determinado grupo. Os documentos que serviram de fonte para essa pesquisa foram analisados levando em consideração a intenção de vinculação de um passado que forja a imagem que se tem o propósito de divulgar.

A ideia da popularização de determinada prática de lazer é para mim especialmente intrigante. Atualmente, estudos que têm o lazer como temática têm reforçado a necessidade de ampliar as possibilidades e vivências do lazer (PINTO et al., 2011; MARCELLINO; CAPI; SILVA, 2011).

Segundo Willians (2007, p. 319) popularizar significa "apresentar o conhecimento de forma em geral acessível". A princípio, uma campanha que tem o intuito de popularizar algo pode ser encarada como a tentativa de se "educar para".

Ao longo da história o teatro já serviu de palco para a construção de sensibilidades tanto conservadoras e elitizadas (CABRAL, 2007, p. 4) quanto revolucionárias (THOMPSON, 1987, p. 331). Segundo Thompson (1987, p. 331), por exemplo:

Em 1789, os "opulentos Mercadores, Armadores, Fabricantes de Cordamos" apresentaram um memorial ao governo, queixando-se de que as apresentações no Teatro da Realeza, perto da Torre, encorajavam "hábitos de devassidão e libertinagem" entre "seus numerosos Manufatureiros, Trabalhadores, Empregados".

Canclini (1980, p. 48) identifica três áreas em que estaria cindida a atividade artística: a arte de elites, a arte para as massas e a arte popular. As três modalidades desenvolvem estéticas diferentes, e possuem diferentes critérios de valor para o julgamento das obras. A primeira prioriza o momento da produção, valoriza a originalidade e deixa o espectador na posição de contemplação; a segunda privilegia a 
distribuição, tem como valor principal a amplitude do público e a eficácia na transmissão da mensagem e seu maior interesse está em transmitir a ideologia burguesa; a terceira centra-se no consumo, não na sua forma mercantil, isto é, a produção e a distribuição estão subordinadas ao uso, à satisfação da população. Para o autor, a arte popular é uma arte de libertação (CANCLINI, 1980, p. 50).

Importante frisar que os três níveis não têm total autonomia e influenciam-se reciprocamente. Inclusive a arte para as massas e a arte de elites pertencem a uma mesma indústria cultural (CANCLINI, 1980, p. 50). A constante comunicação entre as classes sociais presente na sociedade moderna possibilita a influência entre os três níveis.

Canclini (1980, p. 48) acredita na utilização de lugares instituídos hegemonicamente para desenvolvimento de uma estratégia de libertação: "Uma estratégia de libertação deve gerar canais específicos para transmitir suas mensagens, mas deve atuar nos lugares instituídos pelo poder comercial para formar o gosto e a sensibilidade, para ensinar a pensar."

Se a intenção de popularizar determinada prática pode ser interpretada como a vontade de ampliar o número de pessoas que optam por essa atividade, então, para alcançar esse objetivo, seria coerente fazer uma análise das barreiras existentes entre os indivíduos e essa prática. Assim, uma campanha de popularização teria como objetivo a derrubada desses muros. A proposta mais evidente da CPTD é a oferta de espetáculos a "preços populares". Há uma tentativa clara de derrubada de uma barreira financeira. Seria então apenas uma questão econômica? A literatura aponta como negativa a resposta a essa pergunta. Segundo Cabral (2007, p. 4): 
A elitização do teatro se deu em vários aspectos, por um lado a redução das salas de espetáculo, assim como o acesso às mesmas, seja pela localização, seja pelo preço do ingresso; por outro a elitização da "idéia do teatro" sua construção simbólica.

Marcellino (2002) afirma que "democratizar o lazer implica democratizar o espaço". Pode-se pensar que para popularizar o teatro e a dança é necessário fazer com que as pessoas se apropriem dos edifícios teatrais enquanto espaços para o lazer. Em outras palavras, elas precisam se sentir a vontade quando estão no teatro. Para tanto, é preciso que ele perca o ar de "santuário", como afirma Marcellino (2002). Essa construção está relacionada ao imaginário popular existente em torno desses lugares. Diz de uma barreira simbólica, no plano dos significados atribuídos ao espaço.

Melo (2007) afirma que, nas primeiras décadas do século XX, a arte era entendida como elemento de distinção social. Segundo o autor, naquela época se fortaleceu um processo de construção da cultura e da arte como mecanismos de privilégio. Assim, Melo (2007. p. 73) estabelece que o primeiro desafio para pensar a arte como forma de lazer é "reverter essa compreensão de que se trata de algo para poucos, concepção que ainda hoje é mais forte do que a princípio poderíamos conceber".

Outro problema enfrentado na popularização desse equipamento é a centralização dos mesmos. Em sua maioria, eles ficam localizados em uma só região da cidade (MARCELLINO, 2002). Considerando que as camadas menos favorecidas da população vêm sendo expulsas para a periferia, podemos dizer que são essas pessoas que se encontram mais afastadas geograficamente dos teatros da cidade. Segundo Canclini (2003, p. 163), durante a construção do projeto de modernidade, "a população foi dividida sob a oposição centro-periferia: as classes médias e altas nas zonas centrais 
mais bem equipadas, enquanto os pobres se aglomeravam em subúrbios desfavorecidos".

Os muros existentes entre as pessoas e o teatro e a dança aqui apresentados são construções históricas que guardam estreitas relações com a modernidade. Esse tempo é delimitado pela articulação entre o desenvolvimento de um novo modelo econômico, uma nova organização política e a estruturação de um conjunto de novas ideias acerca da vida em sociedade (MELO, 2010, p. 101). A artificialização dos tempos sociais decorrente dessa nova organização social provocou uma mudança na experiência do divertimento, ${ }^{3}$ que passou a ser concebida no chamado tempo livre. Especificamente na América Latina, a modernidade se constrói em meio à dominação produzida historicamente e à mestiçagem cultural dada socialmente, ou seja, um "tempo de desenvolvimento atravessado pelo descompasso da diferença e da descontinuidade cultural" (BARBERO, 2008, p. 216). Mais que afirmação dos novos ditames sociais, o lazer se apresenta também como espaço/tempo privilegiado das tensões e resistências oferecidas ao novo modelo de sociedade moderna.

De acordo com notícia publicada em 2009 pelo jornal Estado de Minas:

Tudo começou em 1972, no Rio de Janeiro. Preocupados com a redução do público - especialmente em dezembro e janeiro -, artistas e produtores propuseram ao Serviço Nacional do Teatro (atualmente extinto) a criação da Campanha das Kombis. Em dezembro, seriam vendidos ingressos dos espetáculos em cartaz na cidade a preços reduzidos. A iniciativa foi um sucesso e, já no ano seguinte, seria estendida para Minas Gerais e São Paulo. ${ }^{4}$

\footnotetext{
${ }^{3}$ No que se refere aos estudos históricos, Melo propõe a adoção do termo diversão como expressão do objeto de estudos ao qual nos debruçamos. O autor considera que o lazer é um "possível arranjo da diversão, e não o único". Para maiores informações, consultar Melo (2011).

${ }^{4}$ Disponível

se.uai.com.br/html/sessao_11/2009/01/02/ficha_teatro/id_sessao=

$<$ http://www.new.divirta-
}

11\&id_noticia $=6389 /$ ficha_teatro.shtml $>$. Acesso em: 20 set. 2012. 
Em 1985 o governo de José Sarney criou o Ministério da Cultura. Em 1986 é aprovada a Lei Sarney, o primeiro dentre outros futuros esforços na concessão de benefícios fiscais para operações de caráter cultural. Inicia-se então um projeto que tem por objetivo deslocar a centralidade do Estado na promoção de ações na área da cultura. Nesse ano a Campanha já era intitulada Campanha de Popularização do Teatro, e em sua programação constava dez peças para adultos e sete para crianças. ${ }^{5}$ Em substituição à Lei Sarney, em 1991 foi criada a Lei Rouanet, que iria ser aprimorada mais tarde no governo Fernando Henrique (CALABRE, 2009, p. 113). A estimulação e ampliação dos recursos privados nas atividades culturais estavam em consonância com a política neoliberal adotada pelo presidente. Para Buarque (2009, p. 43) "o intuito central dessa forma de incentivo é propor uma parceria com o setor privado, considerando que a cultura é uma área de alto interesse para o desenvolvimento social". As parcerias seriam feitas em troca de deduções fiscais.

As leis de incentivos provocaram profundas transformações na área cultural, e a CPTD não escapou dessas mudanças. A nova configuração organizacional assumida pela produção cultural impacta a CPTD de maneira a mudar as perspectivas do projeto. Essa nova estruturação aconteceu a partir da $24^{\mathrm{a}}$ edição, momento que coincide com o início da atual administração. Em entrevista ao site Palco $\mathrm{BH}^{6}{ }^{6}$ em 2001, Rômulo Duque fornece pistas a respeito dessa mudança:

A campanha tinha, em média, um público de nove a doze mil espectadores por ano. No primeiro ano em que eu peguei a Campanha para administrar, dentro da política implantada, nós conseguimos passar para um público de quarenta mil pagantes. No segundo ano, elevamos para sessenta mil. Agora, no terceiro ano, no reinício do

\footnotetext{
${ }^{5}$ Hemeroteca de Belo Horizonte. Estado de Minas, 13-01-1986 - ano LIX - n. 16.948.

${ }^{6}$ Disponível em: <http://www.palcobh.com.br/camarim/janeiro2001/camarim_01.html>. Acesso em: 20 set. 2012.
} 
meu mandato, dentro dessa política de valorização do profissionalismo, fizemos a maior Campanha de Popularização do País, na qual nós levamos cento e vinte mil pessoas ao teatro.

A partir dessa mudança de perspectiva da CPTD é que se delimita o recorte temporal do presente artigo (1998-2012). Em 1998, quando aconteceu a 24 edição, houve um acentuado aumento do público, e essa pareceu ser a principal meta das pessoas que então assumiam a direção. A "política de valorização do profissionalismo", a que Rômulo Duque se refere, seria a responsável pela grande elevação do numero de pessoas que foram aos teatros.

A CPTD assume o importante papel de distribuidora. O slogan da $38^{\mathrm{a}}$ edição foi "\#ARTEQUECONECTA", 7 e o discurso sobre seus resultados publicados no site do Sinparc foi o seguinte: "Com arte, conseguimos conectar 349.624 pessoas que assistiram aos espetáculos de nossa programação". ${ }^{8}$

Apesar de persistir a duvida quanto à eficácia da popularização do teatro e da dança promovida pela CPTD, devido a uma tendência por parte dos críticos a justificar o aumento do público com base na alienação promovida pela cultura de massa, os números apresentados confirmam o aumento quantitativo do público nos meses em que a Campanha acontece. Como se desenvolveram as estratégias de distribuição da CPTD que levaram ao sucesso na tarefa de ampliação do publico?

Analisar a problemática da popularização da arte passa necessariamente pelos meios com os quais ela chega ao povo. Centrar esforços apenas nas relações entre produtores, que representam os artistas e suas criações, e consumidores, que representam o público, é desconsiderar um importante aspecto do fazer artístico na sociedade moderna.

\footnotetext{
${ }^{7}$ Disponível em: <www.sinparc.com.br>. Programação da 38a CPTD. Acesso em: 10 fev. 2012.

${ }^{8}$ Disponível em: <www.sinparc.com.br>. Programação da $38^{a}$ CPTD. Acesso em: 12 mar. 2012.
} 
Canclini (1980, p. 53) propõe uma análise que inclui todos os momentos do processo artístico, que engloba a produção, a distribuição e o consumo. O autor ainda coloca um peso muito grande na distribuição, localizando-a como a chave da dependência (CANCLINI, 1980, p. 45). Isso ocorre porque os distribuidores exercem importante influência tanto na produção quanto no consumo da arte. Exemplo citado por Canclini (1980, p. 45) diz respeito ao artesanato latino-americano. Negociantes trocam o artesanato indígena por objetos que representam muito menos tempo de trabalho e depois revendem fixando-lhes um preço que diz respeito às possibilidades de mercado e não aos custos do produto. Além disso, os distribuidores ainda incentivam os artesãos a modificarem os produtos de acordo com interesses comerciais, alterando a estética da produção. Ainda promovem a falsificação e enganam os consumidores até com relação à procedência. A distribuição pode assim modificar tanto a produção quanto o consumo da arte.

Promover uma popularização da arte passa necessariamente pelos meios com os quais ela é distribuída e ignorar esse aspecto é contribuir com a elitização. Se a distribuição da arte é a chave da dependência, como explica Canclini (1980, p. 45), ela também pode significar independência. Além de promover dominação, a hegemonia passa também pela apropriação por parte do povo dos códigos pelos quais ela acontece.

A CPTD centra esforços justamente na distribuição da arte. Importante ressaltar que isso não significa afirmar que a produção e o consumo estão alheios a esse processo. Nos relatórios oficiais das edições da CPTD estão presentes gráficos que comparam a quantidade de público presente em cada edição. Esses gráficos mostram explicitamente o crescimento do público ao longo do tempo. Além dos gráficos, também aparecem planilhas em que constam as vendas totais referentes a cada edição. 
Para mostrar o sucesso, os números alcançados pela CPTD são constantemente exaltados. Expressões como "Teatro a 8 reais atrai multidão", 9 "Recorde", ${ }^{10}$ "Festival populariza teatro", 11 "público lota auditório", 12 "o final de semana terá 57 espetáculos para o público fazer suas escolhas", 13 "Espetáculos pra mais de cem", ${ }^{14}$ aparecem nas reportagens incluídas nos Relatórios Finais, demonstrando o êxito alcançado na tarefa de distribuição da arte. Os números são apresentados como verdadeiras e irrefutáveis provas da popularização levada a cabo pela CPTD.

Reportagem localizada nos Relatórios Finais resume a proposta:

Seu objetivo é facilitar o acesso da população às peças de teatro e dança, e isso ocorre de duas maneiras: diminuindo o preço das entradas e concentrando esforços na divulgação dos eventos. ${ }^{15}$

A faixa de preço atribuída aos ingressos variou entre quatro e doze reais, sempre de forma crescente ao longo das edições que aconteceram no recorte temporal dessa pesquisa. $\mathrm{O}$ interessante é que desde o principio e independentemente da variação do valor as taxas receberam a denominação de populares. "Variedade e preços

\footnotetext{
${ }^{9}$ Acervo do Sinparc - MG. Relatório Final da 33a CPTD. Jornal Hoje em Dia, 21 de janeiro de 2007. Artigo denominado "Teatro a R $\$ 8$ atrai multidão".

${ }^{10}$ Acervo do Sinparc - MG. Relatório Final da 33 ${ }^{\mathrm{a}}$ CPTD. Jornal Estado de Minas, 9 de janeiro de 2007. Artigo denominado "Recorde".

${ }^{11}$ Acervo do Sinparc - MG. Relatório Final da 36 ${ }^{\mathrm{a}}$ CPTD. Jornal Horizonte Sul, janeiro de 2010. Artigo denominado "Festival populariza teatro". Data: Janeiro de 2010. Caderno de variedades.

${ }^{12}$ Acervo do Sinparc - MG. Relatório Final da 36a CPTD. Jornal do Barreiro, 6 de janeiro de 2010. Artigo denominado "Barreiro tem campanha de popularização do teatro e da dança".

${ }^{13}$ Acervo do Sinparc - MG. Relatório Final da 36 ${ }^{\mathrm{a}}$ CPTD. Jornal Hoje em Dia, 6 de janeiro de 2010. Artigo denominado "Cultura".

${ }^{14}$ Acervo do Sinparc - MG. Relatório Final da $36{ }^{\text {a }}$ CPTD. Jornal O Tempo, 5 de janeiro de 2010. Artigo denominado "Espetáculos pra mais de cem".

${ }^{15}$ Acervo do Sinparc - MG. Relatório Final da $33^{\text {a }}$ CPTD. Jornal Edição do Brasil, 21 a 28 de janeiro de 2007. Artigo intitulado "Campanha de Popularização do Teatro é sucesso".
} 
populares", 16 "Boas peças a preços baixos" 17 são expressões que aparecem com frequência nas reportagens presentes nos Relatórios Finais.

A atribuição de popularidade conferida ao preço não diz respeito propriamente às condições da população. Os preços são delimitados em comparação ao que é comumente cobrado pelos espetáculos ao longo do ano. Isso é observado no Regulamento da $38^{\mathrm{a}} \mathrm{CPTD}:{ }^{18}$

Nos postos de venda da Campanha será aplicada a seguinte faixa de preços: $\mathrm{R} \$ 5,00 ; \mathrm{R} \$ 8,00 ; \mathrm{R} \$ 10,00$ ou $\mathrm{R} \$ 12,00$. Cada produtor estabelecerá a faixa a ser aplicada ao seu espetáculo. A faixa escolhida não poderá ser superior ao valor equivalente à meia entrada cobrada na temporada de apresentações realizadas a partir desta data.

O papel decisivo da distribuição pode ser apreciado no valor fixado como popular. A popularidade do preço é definida pela cobrança de um valor inferior às condições que normalmente se apresentam no mercado ao longo do ano.

A segunda frente de atuação da CPTD no que diz respeito à distribuição da arte está centrada na questão espacial, tanto de localização dos teatros quanto de locais para venda de ingressos.

Além de postos fixos de venda de ingressos, existe também a venda itinerante. Essa novidade foi instituída em 2007, conforme reportagem presente no Relatório Final da $33^{\text {a }}$ CPTD: ${ }^{19}$

\footnotetext{
${ }^{16}$ Acervo do Sinparc - MG. Relatório Final da 36 CPTD. Portal Globo Minas, 7 de janeiro de 2010. Artigo denominado "MG Cultura destaca primeiro fim de semana da Campanha de Popularização do Teatro em BH".

${ }^{17}$ Acervo do Sinparc - MG. Relatório Final da 36 CPTD. Jornal Hoje em Dia, 16 de janeiro de 2010. Artigo denominado "Boas peças a preços baixos".

${ }^{18}$ Disponível em: <www.sinparc.com.br>. Regulamento da 38 Campanha. Acesso em: 6 jul. 2011.

${ }^{19}$ Acervo do Sinparc - MG. Relatório Oficial da 33 a CPTD. Jornal Diário da Tarde, 2 de janeiro de 2007. Artigo denominado "A Campanha vem aí!”.
} 
Outra novidade em 2007 é a venda de ingressos em automóveis, assim como ocorria no início da campanha, em 1973, quando Kombis espalhadas pelo centro da capital comercializavam os bilhetes na até então denominada Campanha das Kombis. [...] Ao longo dos anos, adotou-se os postos de venda fixos no lugar dos veículos e a nova denominação, mas a antiga novidade que retorna este ano promete atrair ainda mais público para os espetáculos.

A atuação dos carros volantes continua e se fez presente na $38^{a}$ edição da CPTD, que aconteceu em 2012. Nessa edição, os postos de venda divulgados foram os seguintes: Mercado das Flores (Av. Afonso pena, esquina com Rua da Bahia), FNACBH Shopping ( $4^{\circ}$ andar), Shopping Cidade (Piso Goitacazes) e Shopping Pátio Savassi (Piso L2). Os postos móveis são localizados em diferentes regiões da cidade: Posto Contagem (estacionamento do Big Shopping), Posto Regional Venda Nova (Av. Padre Pedro Pinto, 1055), Posto Barreiro (Av. Visconde de Ibituruna), Posto Alípio de Melo (Av. Abílio Machado, 2096), Posto Minas Shopping (estacionamento), Posto Praça da Assembléia (Rua Rodrigues Caldas) e Posto Pampulha (Av. Otacílio Negrão de Lima em frente ao parque Guanabara). ${ }^{20}$

A localização dos postos de venda de ingressos mostra a preocupação em cobrir diferentes regiões da cidade, desde as mais favorecidas até as mais pobres. A mesma intenção pode ser observada nas orientações fornecidas a respeito dos deslocamentos até os teatros. Distribuído em 2006, o caderno de divulgação da $36^{\text {a }}$ $\mathrm{CPTD}^{21}$ possui um total de setenta páginas com a programação e sessões como "Onde comprar" e "Localize-se". A última apresenta informações referentes aos lugares aonde é possível estacionar carros próximos aos teatros e também indica as linhas de ônibus que chegam a cada teatro onde a CPTD acontece.

\footnotetext{
${ }^{20}$ Disponível em: <www.sinparc.com.br>. Programação da 38 CPTD. Acesso em: 2 mar. 2012.

${ }^{21}$ Acervo pessoal. Guia Vá ao Teatro - Edição especial - 36 Campanha de popularização teatro e dança. 2010. Distribuição gratuita nos postas de venda da CPTD.
} 
Preocupações com o deslocamento do público até o teatro também ficam evidentes na reportagem "Vá ao Teatro de Metrô", ${ }^{22}$ em que é realizada a divulgação de peças da CPTD que acontecem próximas a diversas estações do metrô da cidade.

A intenção de expandir o alcance da distribuição também pode ser observada na realização de peças no auditório do Colégio São Paulo da Cruz, que está localizado na região do Barreiro, periferia de Belo Horizonte. O caderno de divulgação da $36^{\mathrm{a}}$ $\mathrm{CPTD}^{23}$ possui uma sessão chamada "A campanha acontece também no Barreiro", em que é apresentada a programação específica desse teatro, que consta um total de nove peças.

Extrapolando os limites de Belo Horizonte, a CPTD também chegou a Nova Lima - desde 1998 ou 24a edição, Sabará - desde 1999 ou 25 edição, Contagem desde 2000 ou $26^{\text {a }}$ edição, Juiz de Fora - desde 2002 ou 28 a edição, Vespasiano - desde 2003 ou $29^{\text {a }}$ edição e Ipatinga - desde 2004 ou $30^{\text {a }}$ edição. ${ }^{24}$

Os esforços na direção de ampliação da distribuição podem ser evidenciados por todas essas ações. Porém, ainda existe outro ponto que ganha papel de destaque na efetivação da distribuição: a divulgação.

Falar simplesmente em divulgação dos eventos não contempla toda a complexidade comunicativa da ação da CPTD. Uma mostra da importância ocupada pelos meios de comunicação na organização da CPTD pode ser observada nos Relatórios Finais de suas edições: uma parte completamente dedicada ao trabalho

\footnotetext{
22 Acervo do Sinparc - MG. Relatório Final da 36 ${ }^{\mathrm{a}}$ CPTD. Jornal do Ônibus, janeiro de 2010. Artigo denominado "Vá ao teatro de metrô".

${ }^{23}$ Acervo pessoal. Guia Vá ao Teatro - Edição especial - 36 Campanha de popularização teatro e dança. 2010. Distribuição gratuita nos postas de venda da CPTD.

${ }^{24}$ Acervo do Sinparc - MG. Relatório Final 33 ${ }^{\mathrm{a}}$ CPTD. Campanha de Popularização do Teatro e da Dança: Dados comparativos $24^{\mathrm{a}}$ a $33^{\mathrm{a}}$ CPTD. 2007.
} 
exercido pela assessoria de imprensa. Sua função é a de dar visibilidade à CPTD, bem como contabilizar a visibilidade conquistada.

A atuação da assessoria de imprensa vai desde a organização da coletiva para o lançamento da CPTD, passa pela sugestão de pautas a ser abordadas pelos veículos de comunicação e pela divulgação do balanço de vendas de ingressos, até a quantificação do espaço conquistado nos veículos impressos, sites e mídia eletrônica (rádio e televisão).

O detalhamento das condições de exibição da CPTD na mídia é feito de forma exclusivamente quantitativa. No caso da televisão e do rádio, o tempo específico de exibição em cada programa de cada emissora é contabilizado. Já para os sites e jornais, os centímetros dedicados à CPTD são calculados para a posterior soma total desse espaço.

Toda essa quantificação é apresentada em termos de custo-benefício. Seguem dois trechos do relatório da assessoria de imprensa presente no Relatório Final da $32^{\mathrm{a}}$ CPTD: ${ }^{25}$

O espaço conquistado nos veículos impressos e sites foi de 18218,61 $\mathrm{cm}$, que se comparado ao custo de mídia paga corresponderia à cerca de R\$ 2.732.791,5 (dois milhões, setecentos e trinta e dois mil, setecentos e noventa e um reais e cinco centavos).

O total do tempo de exposição na mídia eletrônica - televisão e rádio - foi de 14h31'26"', perfazendo uma estimativa global de investimentos de R $\$ 1.038 .153,50$ (um milhão, trinta e oito mil, cento e cinquenta e três reais e cinquenta centavos), sendo o tempo de televisão $07 \mathrm{~h} 03^{\prime} 25^{\prime \prime}$ e rádio $07 \mathrm{~h} 24^{\prime} 01^{\prime \prime}$, e o equivalente em investimentos, respectivamente, $\mathrm{R} \$$ 903.560,50 (novecentos e três mil, quinhentos e sessenta reais e

${ }^{25}$ Acervo do Sinparc - MG. Relatório Final 32 ${ }^{\mathrm{a}}$ CPTD. Relatório de assessoria de imprensa. 
cinquenta centavos) - Televisão - e $\mathrm{R} \$ 134.593,00$ (cento e trinta e quatro mil quinhentos e noventa e três reais) - Rádio.

A forma como está organizado o relatório da assessoria de imprensa deixa claro que a atuação não é direcionada somente ao público. A divulgação exerce um papel duplo: o de atrair tanto o público quanto os patrocinadores.

A relação existente entre a divulgação e os patrocinadores pode ser entendida sob a prática do marketing cultural. As leis de incentivo à cultura reorganizaram a produção cultural de forma a introduzir no cenário uma intensa intervenção da dimensão econômica, que, incentivadas pela própria lei, experimentam outras formas de comunicação com a sociedade. A comunicação exercida através do marketing cultural não se restringe ao entendimento da propaganda. Segundo Rubim (1997, p. 3),

O marketing cultural deve ser entendido como uma zona instável de trocas, nas quais se intercambiam recursos financeiros e valores, imanentes ao produto cultural ou dele derivados, como prestígio e legitimidade, repassados sob a forma de qualidades agregadas a uma imagem social. Tal negociação de produtos tão díspares - recursos financeiros por produção de imagem pública e vice-versa - não pode ser formulada como necessariamente harmônica, como idealizam muitos textos dedicados ao tema.

O caráter desarmônico conferido a essa transação se dá pela hegemonia do capital. Um olhar apenas sob essa ótica coloca a arte - ou a cultura - como um instrumento a ser utilizado pelas empresas com o intuito de incentivar o consumo de seus produtos. Mais, como uma mercadoria que não guarda nenhum valor intrínseco ao fazer artístico, já que a atuação do capital não se dá em um momento posterior à criação da obra, e sim a submete a uma formatação específica que atende aos interesses hegemônicos desde a sua produção. 
Para Barbero (2008, p. 281), esse entendimento privou os meios de comunicação de densidade cultural, e os converteu em meras ferramentas de ação ideológica. O autor propõe como alternativa um estudo não só quantitativo e temático da comunicação, ou seja, aquele que a analisa a partir dos interesses econômicos que movem as empresas, mas um estudo também qualitativo, que compreenda a natureza comunicativa que recai sob a cultura e seu caráter de processo produtor de significações (BARBERO, 2008, p. 289).

O desafio representado pela indústria cultural aparece com toda a sua densidade no cruzamento dessas duas linhas de renovação - que inscrevem a questão cultural no interior do político e a comunicação na cultura. (...) $\mathrm{O}$ que já não fará sentido é continuar programando políticas que separam aquilo que acontece na Cultura - maiúscula daquilo que acontece nas massas - na indústria e nos meios massivos de comunicação. (BARBERO, 2008, p. 289)

O trato instrumentalizado sempre conferido à comunicação fez com que as análises a respeito do marketing cultural fossem em relação aos benefícios conquistados pelas empresas às custas da precarização da produção cultural. Ou o contrário, assumindo uma postura ingênua frente à atuação do poder. O novo olhar que recai sob a comunicação quando localizada no interior da cultura cria um novo horizonte de problemas e dá margem a outras análises, que consideram tanto a utilização da cultura como instrumento do marketing empresarial, como o uso do instrumental do marketing para a produção cultural.

Os usos do instrumental do marketing bem como das leis de incentivo ficam explícitos na forma como a CPTD apresenta o relatório da assessoria de imprensa. O custo benefício do investimento empresarial na CPTD fica evidenciado de forma 
bastante positiva, com números que não deixam dúvidas quanto aos custos maiores que representariam tamanha exposição sem o suporte da CPTD.

O que não pode deixar de ser destacado é que a maioria das reportagens veiculadas sequer cita os patrocinadores. Suas marcas ganham mais destaque nos cadernos de divulgação da programação e nos vídeos passados nos teatros antes do começo das peças, coisas que nem aparecem na contabilização dos números referentes à visibilidade da CPTD. No caderno de divulgação distribuído em $2010^{26}$ aparecem seis marcas de empresas patrocinadoras e mais seis que apoiam o evento. Já no Relatório Final da $36^{\mathrm{a}} \mathrm{CPTD},{ }^{27}$ em que constam as reportagens impressas veiculadas naquele ano, somente aparece a marca de uma empresa. Nesse sentido, em termos qualitativos a grande exposição da CPTD é mais direcionada ao público do que propriamente aos patrocinadores. Porém, ela é contabilizada em termos do custo benefício oferecido aos últimos.

É claro que a presença de patrocinadores interfere não só na distribuição, mas também na produção e no consumo da arte. Retomando o exemplo de Canclini (1980, p. 45) a respeito do artesanato latino-americano, fica explicito que pode haver modificações nas obras para atender à demanda do patrocinador. Porém, no caso específico de que trata essa pesquisa, a mediação entre os artistas e os patrocinadores exercida pela CPTD cria uma distância entre essas duas figuras do processo artístico. Assim, a atuação dos patrocinadores parece não acontecer diretamente no momento da produção da obra de arte, embora não se possa afirmar que não exista relação alguma entre o patrocínio e a concepção das peças de teatro e dança que compõem a CPTD.

\footnotetext{
${ }^{26}$ Acervo pessoal. Guia Vá ao Teatro - Edição especial - 36 Campanha de popularização teatro e dança. 2010. Distribuição gratuita nos postas de venda da CPTD.

${ }^{27}$ Relatório Final da $36^{\mathrm{a}}$ CPTD. Acervo do Sinparc - MG.
} 
A hipótese de que a presença dos patrocinadores reduz a arte a comercio não se sustenta quando inserimos a situação na história. Artistas consagrados como Michelangelo e Caravaggio produziram muitas obras encomendadas por clientes e nem por isso deixou-se de conferir o status de obra de arte ao objeto criado, muito menos foram destituídos do posto de artistas.

Os meios de comunicação são peça chave na estratégia de distribuição da CPTD. Até aqui foi discutido a articulação deles com os patrocinadores, porem, os meios de comunicação também promovem uma articulação mais efetiva com o público.

Duas características relativas à CPTD estão presentes em todas as capas dos cadernos de divulgação distribuídos à população: o tempo e o espaço em que ela acontece.

O tempo é destaque logo no título de todas as edições: $24^{\mathrm{a}}, 25^{\mathrm{a}}, 26^{\mathrm{a}}$ CPTD e assim por diante até chegar à última versão, a $38^{\mathrm{a}}$, que ocorreu em 2012. A temporalidade é sempre anunciada, o que contribui para a construção de uma ideia de tradição em torno da CPTD. Os 38 anos de existência dão segurança, consistência nas ações. Além de legitimarem a atuação continuada, também conectam o presente e o passado, construindo sentidos compartilhados. A evolução ao longo do tempo mostra que a edição atual é sempre melhor que a anterior, e firma um compromisso entre a CPTD e a população: o de fazer com que uma edição supere a outra em termos de quantidade de público. A tradicionalidade conferida pelo tempo é o que fornece condições para esse trato. 
Segundo Rômulo Duque, presidente do Sinparc e coordenador da Campanha, a expectativa para este ano é a de sempre, ou seja, superar a do ano anterior. "A meta é ultrapassar o recorde do ano passado". ${ }^{28}$

Em 2012, ano referente a sua $38^{\mathrm{a}}$ edição, a CPTD tinha como uma das atrações o que foi denominado "Projetos Especiais" ${ }^{29}$. Um desses projetos era o seguinte: “Exposição Campanha de Popularização Teatro e Dança: 38 anos fazendo arte”. O slogan anunciava 38 anos, porém na exposição somente apareceram informações a respeito da $34^{\mathrm{a}}, 35^{\mathrm{a}}, 36^{\mathrm{a}}, 37^{\mathrm{a}}$ e $38^{\mathrm{a}}$ CPTD. Efetivamente foram expostos apenas cinco anos, mas o que é constantemente exaltado e anunciado são os 38, inclusive pelo título da exposição.

O que está em jogo em uma exposição como essa não é exatamente o passado, ou a nostalgia da recordação. O investimento que é feito é no estabelecimento de uma memória que tem a função de "dar continuidade ao processo de construção permanente da identidade ${ }^{30}$ coletiva" (BARBERO, 2008, p. 258).

O espaço também é um importante articulador das relações entre a CPTD e a população. Belo Horizonte é apresentada como o local onde a CPTD alcançou seu auge. A cidade é o palco da Campanha, que compartilha seu sucesso com as produções artísticas locais. A bandeira da valorização da arte local é levantada a todo o momento. O slogan é o de que temos arte e cultura e precisamos prestigiá-los. A população é convocada a comprovar a efervescência cultural existente na cidade através do seu comparecimento aos teatros.

\footnotetext{
${ }^{28}$ Disponível em: <http://www.agendabh.com.br/turismo_detalhes.php?CodEve=1739>. Acesso em: 20 ago. 2012.

${ }_{29}$ Acervo pessoal. Caderno de divulgação da $38^{\mathrm{a}} \mathrm{CPTD}$, distribuído à população nos locais de compra de ingressos.

${ }^{30} \mathrm{O}$ presente texto não tem como objetivo trabalhar os conceitos de identidade e sim o relacionamento entre a CPTD e a população de Belo Horizonte. Para tanto, foi utilizado como referência o conceito apresentado por Hall (2003, p. 12), que entende a identidade como "uma celebração móvel: formada e transformada continuamente em relação às formas pelas quais somos representados ou interpelados nos sistemas culturais que nos rodeiam".
} 
A exposição "Campanha de Popularização Teatro e Dança: 38 anos fazendo arte" mostrou os conceitos das cinco últimas edições. O da $37^{\mathrm{a}}$ era o seguinte:

Conceito: "O todo não é todo sem as partes". Partindo desse conceito, buscamos mostrar que a arte só acontece, que a campanha só se faz, com a participação de todos. Assim como em um quebra-cabeça, cada peça é importante. Foi criado o slogan "Tô na Campanha" e com ele, as pessoas confirmavam sua participação. ${ }^{31}$

Assim, foi transferida a cada um a responsabilidade na execução desse projeto que sempre foi de/para todos. O slogan "Tô na Campanha” anunciava quem cumpriu com o acordo, quem assumiu seu papel e ajudou a fazer de BH uma referência artística nacional.

Ao final de cada temporada, os números de ingressos vendidos são apresentados como uma vitória não apenas da CPTD, mas da cidade toda, que compareceu e provou que a cada ano que passa Belo Horizonte se consolida mais como um polo de arte e cultura no Brasil e no mundo.

As relações entre a população e a CPTD são articuladas através do tempo e do espaço. Está completo o jogo da identidade: Existimos há 38 anos e fizemos de Belo Horizonte um polo de cultura e arte. A CPTD se incorpora à história da cidade, e consequentemente também à história de sua população. Para "entrar para a história" foi necessário o desenvolvimento de um senso comum, uma representação coletiva a respeito do que a CPTD significa para Belo Horizonte. A produção de um sentido com o qual os belo-horizontinos puderam se identificar.

A integração em torno de um significado comum só foi possível pela mediação exercida pela cultura de massa, que encobre diferenças e unifica os gostos. Porém, essa

\footnotetext{
31 Acervo pessoal. Conceito publicado na exposição "Campanha de Popularização Teatro e Dança: 38 anos fazendo arte”. Fnac BH Shopping, 12 de janeiro a 4 de março de 2012.
} 
uniformização não se deu pela pura ação da hegemonia. A cultura de massa só se tornou mediadora do processo de conciliação entre as classes uma vez que ela foi constituída a partir do popular, "acionando e deformando ao mesmo tempo sinais de identidade da antiga cultura popular [...]" (BARBERO, 2008, p. 175).

Segundo Hall (2003, p. 253) o termo popular assume uma variedade de significados e entre eles o que mais corresponde ao senso comum é aquele que considera que "algo é popular porque as massas o escutam, compram, leem, consomem e parecem apreciá-lo imensamente". Apesar de reconhecer que esse entendimento é comercial e está corretamente associado à manipulação da cultura do povo, Hall (2003, p. 253) apresenta duas restrições a dispensá-lo completamente: (1) A visão de que o povo é uma força mínima, passiva e ignorante no que diz respeito à própria dominação, não perdurará por muito tempo como uma explicação adequada dos relacionamentos culturais; (2) Com o objetivo de resolver a questão, é comum fazer-se a contraposição dessa cultura "popular comercial" com outra que seria a "verdadeira" cultura do povo, alternativa, autêntica. Assim, a cultura popular fica situada fora do campo de força das relações de poder e dominação culturais (HALL, 2003, p. 254).

A definição do termo popular correspondente ao senso comum e comercial não deve ser descartada porque ela nos faz pensar a complexidade das relações culturais. Chama a atenção para a polarização em que está preso o estudo da cultura popular: "entre a autonomia pura ou o total encapsulamento" (HALL, 2003, p. 254). Os espetáculos de teatro e dança presentes na programação da CPTD não podem ser classificados tendo como referência essa polarização.

Se as formas de cultura popular comercial disponibilizadas não são puramente manipuladoras, é porque, junto com o falso apelo, a redução de perspectiva, a trivialização e o curto-circuito, há também 
elementos de reconhecimento e identificação, algo que se assemelha a uma recriação de experiências e atitudes reconhecíveis, às quais as pessoas respondem. (HALL, 2003, p. 255)

As identificações que permitem a inserção da CPTD na história de Belo Horizonte podem ser apreciadas principalmente em dois aspectos: (1) apresentação da CPTD como um evento que coloca em evidência a arte produzida na cidade; (2) esforço de aproximação entre as características da CPTD e as características de Belo Horizonte.

"Nada como a CPTD, ontem lançada em $36^{\mathrm{a}}$ edição, para mostrar que há mais vida cultural na capital mineira do que supõem os seus moradores". ${ }^{32}$ Essa e outras fontes do presente estudo mostram que o discurso é o de que a CPTD coloca a produção artística de $\mathrm{BH}$ em um lugar de destaque, e o faz como se estivesse apenas fazendo justiça, apenas dando a ela o que é de direito. A valorização da arte regional promovida pela Campanha é um mecanismo de identificação. Passa uma boa imagem da cidade, divulga o que ela tem de bom, de melhor, e com isso consegue mais adesão dos moradores. Segundo Hall (2003, p. 39):

A identidade surge não tanto da plenitude da identidade que está dentro de nós como indivíduos, mas de uma falta de inteireza que é "preenchida" a partir de nosso exterior, pelas formas através das quais nós imaginamos ser vistos por outros.

$\mathrm{O}$ reconhecimento de que em $\mathrm{BH}$ existem boas produções teatrais que precisam apenas de maior visibilidade é o que justifica a necessária popularização promovida pela CPTD. Assim, o evento é carregado de importância: é ele que mostra para a própria população e também para o resto do Brasil o quão movimentada é a vida cultural na capital mineira.

\footnotetext{
${ }^{32}$ Acervo do Sinparc - MG. Relatório Final da 36 CPTD. Jornal O Tempo, 6 de janeiro de 2010. Artigo denominado "Palco Iluminado", autoria de Raquel Faria.
} 
Para impulsionar a popularização não faltam elogios à arte local: "A capital será palco de memoráveis apresentações de dança e teatro, numa campanha que tradicionalmente movimenta e aquece nossa cultura",33 "a partir do dia 5 de Janeiro, Belo Horizonte se torna a capital dos espetáculos", 34 "a CPTD começa hoje com a missão de aproximar o cidadão da arte produzida na cidade", 35 "a arte em evidência na capital mineira", 36 "este evento é mais uma prova da liderança cultural de Minas". 37

Apesar dos elogios ao teatro e à dança regionais, e do esforço de propagação desse título, as ações da CPTD declaradamente não estão preocupadas exatamente com a qualidade das obras artísticas. O trecho de reportagem destacado abaixo esclarece como a organização do evento age frente às questões estéticas das obras:

"Todos os participantes têm que ser profissionais gabaritados pelo SATED ${ }^{38}$ exigimos também que sejam empresas, para aumentar ainda mais esse profissionalismo, e terem cumprido uma temporada de pelo menos doze apresentações na cidade", sintetiza Rômulo Duque. Só o quesito qualidade não entre em discussão. "Ninguém acha seu filho feio", compara. "Discutir o perfil estético e a linguagem dos trabalhos é uma questão que colocamos para o público". Então, faça a escolha certa. ${ }^{39}$

$\mathrm{O}$ fato de os elogios à arte mineira não serem necessariamente baseados na qualidade simplesmente não vem ao caso. O que interessa é a criação de um ambiente favorável à ida aos teatros para prestigiar as peças.

\footnotetext{
${ }^{33}$ Acervo do Sinparc - MG. Relatório Final da 32 CPTD. Jornal O Tempo, 12 de janeiro de 2006. Artigo denominado "Popularização do Teatro", autoria de Elder José Martinho.

${ }^{34}$ Acervo do Sinparc - MG. Relatório Final da 32 ${ }^{\text {a }}$ CPTD. Jornal Globo Minas, 4 de janeiro de 2006. Artigo denominado "Belo Horizonte se prepara para receber a 32a Campanha de Popularização do Teatro e da Dança".

${ }^{35}$ Acervo do Sinparc - MG. Relatório Final da 33 ${ }^{\text {a }}$ CPTD. Jornal Estado de Minas, 4 de janeiro de 2007. Artigo denominado "Pólo Cultural", autoria de Ailton Magioli.

${ }^{36}$ Acervo do Sinparc - MG. Relatório Final da 36 CPTD. Jornal Horizonte Sul, janeiro de 2010. Artigo denominado "A arte em evidência na capital mineira".

${ }^{37}$ Disponível em: < http://www.estadao.com.br/arquivo/arteelazer/2001/not20010104p6734.htm>. Acesso em: 23 set. 2012.

${ }^{38}$ Sindicato dos Artistas e Técnicos em Espetáculos de Diversões do Estado de Minas Gerais.

${ }^{39}$ Acervo do Sinparc - MG. Relatório Final da 36 a CPTD. Jornal Super Notícias, 8 de Janeiro de 2010. Artigo denominado "A Alta temporada do Teatro Mineiro: para evitar a presença de aventureiros".
} 
Para fomentar mais ainda a ideia compartilhada de que em $\mathrm{BH}$ existe uma efervescência artística, as comparações com outros lugares aparecem constantemente: "Depois da dança, Minas Gerais inova mais uma vez trazendo a ópera para a Campanha, que continua restrita ao teatro no eixo Rio - São Paulo", 40 "o maior evento de teatro e dança do país está sendo realizado na capital mineira", 41 "considerada a maior do gênero no país", 42 "é atualmente o maior deste segmento no Brasil e um dos maiores do mundo em público e duração". ${ }^{4}$

Segundo Hall (2003, p. 40) a identidade é construída em relação ao outro, que evidentemente o eu não pode ser. As comparações acontecem para determinar as características que são exclusivas, que não aparecem em nenhum outro local. Essa diferenciação é a base das relações identitárias.

Em entrevista ao guia "Vá ao Teatro", o presidente do Sinparc também utiliza comparações:

Nós temos aqui uma efervescência cultural como poucos lugares deste país, mas nem isso é suficiente para garantir trabalho decente para todos o ano inteiro. Temos praticamente os melhores em tudo. Somente para enumerar alguns, temos o melhor grupo de dança do país; o melhor grupo de teatro de rua do país; o maior projeto de popularização do teatro e da dança; o mais importante Festival de Teatro Internacional; o maior grupo de Teatro de Bonecos. Apesar disto e, independente do sucesso, estamos sempre começando tudo do zero. $^{44}$

\footnotetext{
${ }^{40}$ Acervo do Sinparc - MG. Relatório Final da 33a CPTD. Jornal Diário de Tarde, 4 de janeiro de 2006. Artigo denominado "Ópera popular”, autoria de Ailton Magioli.

${ }^{41}$ Acervo do Sinparc - MG. Relatório Final da 36 CPTD. Jornal de Paraopeba, janeiro de 2010. Artigo denominado " $36^{\text {a }}$ Campanha de Popularização do Teatro e Dança".

42 Acervo do Sinparc - MG. Relatório Final da 36 a CPTD. Jornal Turismo de Minas, janeiro de 2010. Artigo denominado "Geraldo Magela, muito além do humor", autoria de Mara Bianchetti.

${ }^{43}$ Acervo do Sinparc - MG. Relatório Final da 36a CPTD. Guia Entrada Franca, janeiro de 2010. Artigo denominado "Especial 36 Campanha de Popularização do Teatro e da Dança".

${ }^{44}$ Disponível em: <http://www.sinparc.com.br/ingressobh/entrevista.php>. Acesso em: 23 set. 2012.
} 
Tudo que contribua para a construção de uma identidade simpática a frequentar os teatros é bem vindo. Inclusive como atração nas férias para aqueles que permanecem em BH, em substituição à ida ao litoral.

Em janeiro Belo Horizonte sofre uma mudança radical. Cerca de 800 mil pessoas deixam a capital mineira para curtir as tão esperadas férias, que geralmente acontecem no litoral. Só para se ter uma idéia, Minas Gerais é o segundo maior emissor de turistas no Brasil. Mas além da calmaria no trânsito, quem fica em Belo Horizonte durante o primeiro mês do ano pode desfrutar de um dos maiores eventos culturais do país. ${ }^{45}$

Essa reportagem mostra o reconhecimento de que não possuímos praia, mas em compensação temos teatro, dança e arte, sintetizados simplesmente em um dos maiores eventos culturais do país. A intenção é convencer que não é preciso sair de BH para ter boas férias, chamar a atenção para a possibilidade de passar as férias aqui mesmo, insinuar que temos atrações no período das férias que inclusive podem ser melhores que o litoral.

A constatação de que BH não é local para se passar as férias é especialmente cara aos belo-horizontinos. O discurso da CPTD é justamente de inversão desse imaginário popular. Outras fontes dessa pesquisa também sugerem a CPTD como grande atração para esse período, e motivo para ficar na cidade: "Diversão é a palavra de ordem para a garotada que está de férias e que não vai sair de $\mathrm{BH}$ neste início de ano", 46 "quem não vai viajar neste fim de semana pode se divertir com um programa para toda a família". ${ }^{47}$

\footnotetext{
45 Acervo do Sinparc - MG Relatório Final da 33 ${ }^{\mathrm{a}}$ CPTD. Jornal Buritis, janeiro de 2007. Artigo denominado "Janeiro, o mês do teatro em BH".

${ }^{46}$ Acervo do Sinparc - MG. Relatório Final da 33 $3^{\mathrm{a}}$ CPTD. Jornal Estado de Minas, Gurilândia, 6 de janeiro de 2007. Artigo denominado "Espaço para atores mirins".

${ }_{47}$ Acervo do Sinparc - MG. Relatório Final da $33^{\mathrm{a}}$ CPTD. Jornal Diário da Tarde, 15 de fevereiro de 2007. Artigo denominado "Boas opções para o público infantil".
} 
O período do carnaval também recebe tratamento semelhante:

A programação, que segue até o fim deste mês, perde fôlego a partir desta semana, quando a maioria dos espetáculos interrompe suas exibições, já em clima de carnaval. Apesar da cidade vazia, quando muitos belo-horizontinos viajam para curtir o feriado, algumas peças se mantêm em cartaz, inclusive, abriram sessões extras de suas atrações, provando que é possível competir até mesmo com um dos eventos mais aguardados do calendário nacional. ${ }^{48}$

Em 2009, a CPTD fez parte de um programa cujo objetivo era o de atrair turistas para a cidade:

Mais uma novidade é que a Campanha participa do projeto $\mathrm{BH}$ ESPERA POR VOCÊ, do Belo Horizonte Convention \& Visitors Bureau, que está incentivando turistas de todo Brasil e outros países a vir a Belo Horizonte entre os meses de Janeiro e Fevereiro. ${ }^{49}$

Além do investimento na concretização de um acordo tácito entre os cidadãos de $\mathrm{BH}$ de que aqui a cultura e a arte têm força e são valorizadas, há também a tentativa de exportação dessa ideia. É preciso fazer disso um fato não apenas regional, mas nacional. Queremos ser reconhecidos assim.

A valorização e divulgação da arte regional são intimadas, mas a CPTD também lança mão de mais recursos para a consolidação das relações identitárias. A $34^{\text {a }}$ edição não deixa dúvidas quanto à intenção de unir a história da CPTD a de BH. O seguinte conceito foi apresentado na exposição "Campanha de Popularização Teatro e Dança: 38 anos fazendo arte":

\footnotetext{
${ }^{48}$ Acervo do Sinparc - MG. Relatório Final da 33 $3^{\mathrm{a}}$ CPTD. Jornal Diário da Tarde, 12 de fevereiro de 2007. Artigo denominado "Folia nos palcos de BH".

49 Disponível em: <http://www.agendabh.com.br/turismo_detalhes.php?CodEve=1739>. Acesso em: 20 ago. 2012.
} 
Conceito: "Faz parte da história de Belo Horizonte". Com este slogan, trabalhamos a marca da campanha em diversos monumentos da cidade, mostrando que, assim como a arquitetura marcante, a Campanha de Popularização Teatro e Dança está na história da cidade. $^{50}$

Nessa edição, a capa do caderno de divulgação era a seguinte:

FIGURA - $38^{\mathrm{a}}$ Campanha de Popularização do Teatro e da Dança

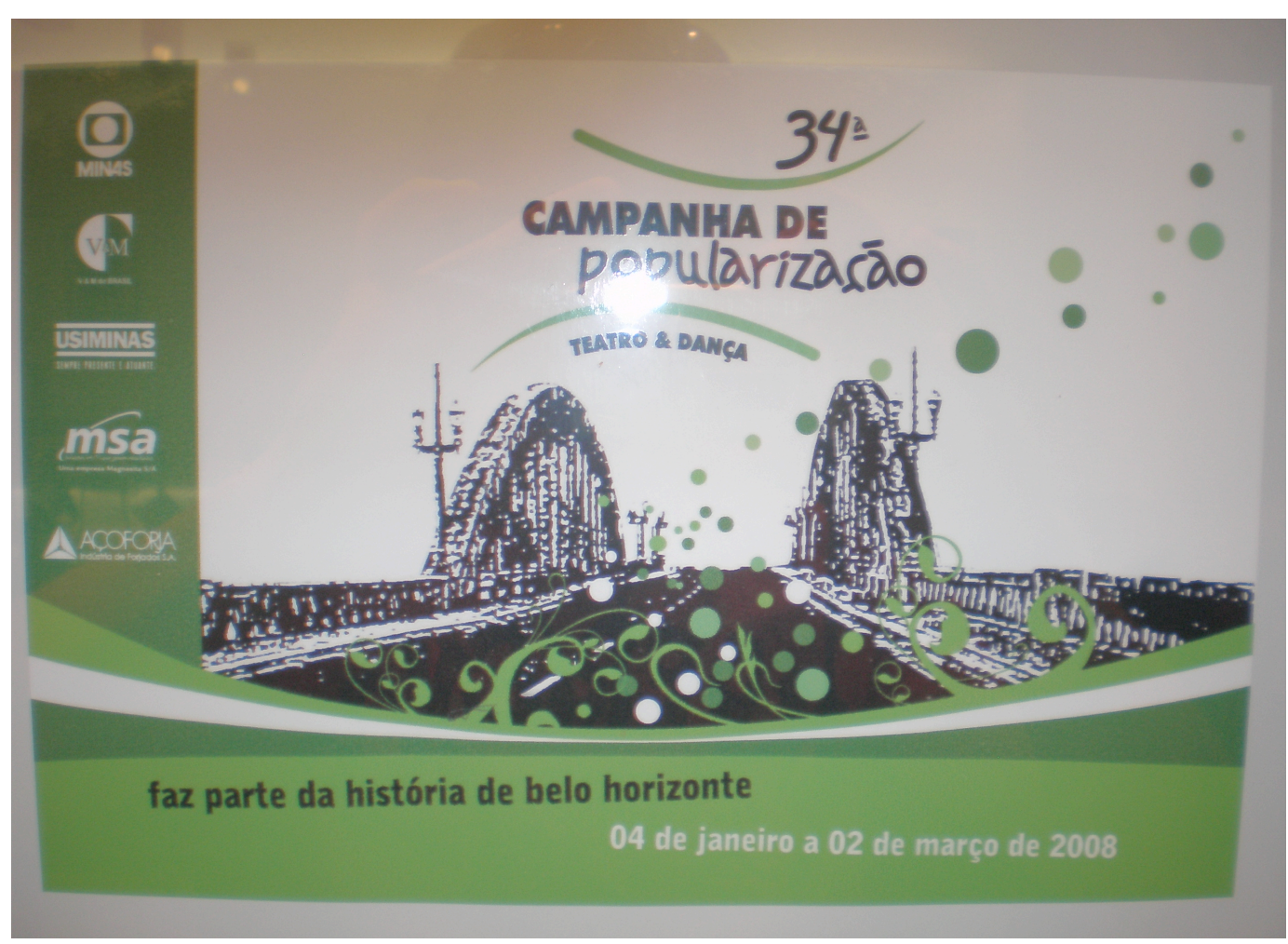

Fonte: Acervo pessoal. ${ }^{51}$

Fica clara a tentativa de misturar a CPTD ao que já é conhecido em $\mathrm{BH}$, e assim fazer com que o evento fique cada vez mais inserido não só no calendário da cidade, mas também na vida da população.

\footnotetext{
${ }^{50}$ Acervo pessoal. Conceito publicado na exposição "Campanha de Popularização Teatro e Dança: 38 anos fazendo arte". Fnac BH Shopping, 12 de janeiro a 4 de março de 2012.

${ }^{51}$ Imagem obtida na exposição "Campanha de Popularização Teatro e Dança: 38 anos fazendo arte". Fnac BH Shopping, 12 de janeiro a 4 de março de 2012.
} 
Outro indício desse esforço é o "Butecando na Campanha", realizado na edição de 2010, a 36'. "Dentre as novidades desta edição está a criação do 'Butecando na Campanha', um bar oficial do projeto, que servirá de ponto de encontro entre artistas, produtores e o público". 52

Com o Butecando, a CPTD toma emprestada a fama já consagrada de BH ser a capital dos bares. Oferecendo a oportunidade de usufruir da arte e da cultura em um bar, é promovida uma extensão da CPTD que chega até onde reconhecidamente o belohorizontino se sente à vontade. Assim, uma identificação é promovida com um espaço que já é familiar.

É claro que a própria ideia da capital dos bares também é uma representação, também foi construída para ativar a produção de sentidos partilhados, porém essa ligação só é possível a partir do acionamento e deformação de expressões populares. Assim, é exercida pela cultura de massa uma mediação entre as formas culturais e a demanda comercial.

O que acontece é a construção de significados que organizam e influenciam não só as nossas ações, mas também a concepção que temos de nós mesmos. Atinge, portanto, a nossa identidade. Mas não é completamente exterior a ela, uma vez que foi construído na tensão entre o que é familiar e o que constitui a fórmula mercantil.

Diante do exposto, já em direção às considerações finais do presente artigo, podemos entender a centralidade das ações de distribuição da CPTD divididas em três eixos: (1) criando formas de facilitar o acesso, tanto no que diz respeito aos preços, quanto aos deslocamentos; (2) promovendo uma intensa divulgação nos meios de comunicação em massa, divulgação essa que tem pretensões de atrair tanto público

\footnotetext{
52 Acervo do Sinparc - MG. Relatório Final da 36 ${ }^{\text {a }}$ CPTD. Jornal Turismo de Minas, janeiro de 2010. Artigo denominado "Geraldo Magela, muito além do humor", autoria de Mara Bianchetti.
} 
quanto patrocinadores, e; (3) estabelecendo relações de tradição que geram vínculos com a população e com a cidade.

Para chegar ao povo, e assim popularizar-se, a arte precisa ser modificada em sua concepção. A arte elitista, como explica Canclini (1980, p. 49), ignora a distribuição e centra toda importância no momento da produção. Ao público, cabe a contemplação. Porém, poucos possuem poder aquisitivo e condições de tempo para o ócio para levar a cabo essa contemplação. Portanto, a arte que quer popularizar-se precisa "demonstrar seus laços com a estrutura da sociedade e da linguagem convencional, pode facilitar, para um público maior, a compreensão e o gozo da elaboração realizada pelos artistas” (CANCLINI, 1980, p. 37).

Para promover a popularização, é preciso diminuir a distancia entre produção e consumo, entre criação e compreensão. Entre o produtor e o consumidor está o distribuidor, que impulsiona a organização do processo artístico na sociedade capitalista. Para Canclini (1980, p. 45), a distribuição “(...) faz com que as obras cheguem aos espectadores, determina as condições em que chegarão, e que espectadores poderão ou não conhecê-las". O poder da distribuição pode ser visto inclusive na possibilidade de imposição de critérios estéticos, o que denuncia a falsa liberdade de criação absoluta dos artistas. O autor afirma ainda que "não pode haver uma política artística popular sem uma organização radical do processo de distribuição" (CANCLINI, 1980, p. 47). A organização sugerida por Canclini ganha contornos na atuação da CPTD. As estratégias de distribuição apresentadas aqui representam a aposta da Campanha. Resta saber se essa distribuição levada a cabo pela CPTD é radical o suficiente para promover popularização, para potencializar a arte popular. 
Aos pesquisadores instigados pelas relações entre a distribuição e a popularização da arte, interessa, por exemplo, construir uma história da frequência aos teatros, e de como as dinâmicas de ocupação dos espaços e criação das peças modificou essa freqüência. Tudo isso inserido na história do teatro como um todo, que comporta também a história dos atores, das peças, dos espaços cênicos, entre outras. Ao historiador do lazer interessa uma história dos modos de recepção das diversões propostas, bem como uma história das dinâmicas de distribuição das diversões que caíram ou não em gosto popular.

\section{REFERÊNCIAS}

BARBERO, Jesus Martín. Dos meios às mediações: comunicação, cultura e hegemonia. 5. ed. Rio de Janeiro: Editora UFRJ, 2008.

BUARQUE, Isabela Maria A. G. A formação recente do campo da dança (19801990): uma análise comparada da trajetória de duas companhias cariocas. Dissertação (Mestrado em História Comparada) - Universidade Federal do Rio de Janeiro, Rio de Janeiro, 2009.

CABRAL, Michelle Nascimento. Rompendo fronteiras: Lazer, teatro e espaço público. Licere, Belo Horizonte, v. 10, n. 1, abr., 2007.

CALABRE, Lia. Políticas culturais no Brasil: dos anos 1930 ao século XXI. Rio de Janeiro: Editora FGV, 2009.

CANCLINI, Nestor García. A globalização imaginada. São Paulo: Iluminuras, 2003.

CANCLINI, Nestor García. A socialização da arte. São Paulo: Cultrix, 1980.

HALL, Stuart. A identidade cultural na pós-modernidade. Rio de Janeiro: Ed. DP\&A, 2003.

HALL, Stuart. Da diáspora: identidades e mediações culturais. Belo Horizonte: Editora UFMG, 2003a.

MARCELLINO, Nelson Carvalho. Estudos do Lazer. Uma Introdução. 3. ed. Campinas: Autores Associados, 2002.

MARCELLINO, N. C.; CAPI, A. H. C.; SILVA, A. M. Lazer no município: formação e desenvolvimento de quadros. In: ISAYAMA, H. F. (Org.). Gestão de políticas de esporte e lazer: experiências, inovações, potencialidades e desafios. Belo Horizonte: Editora UFMG, 2011. p. 229-246. 
MELO, Victor Andrade de. Arte e lazer: desafios para romper o abismo. In: MARCELLINO, Nelson Carvalho (Org.). Lazer e Cultura. Campinas: Alínea, 2007. p. 65-88.

O lazer e a modernidade: representações. In: . (Org.). Lazer: olhares multidisciplinares. Campinas: Alínea, 2010.

PINTO, L. M. S. de M. et al. Desafios para a gestão das políticas de lazer no Brasil. In: ISAYAMA, H. F. et al. (Org.). Gestão de políticas de esporte e lazer: experiências, inovações, potencialidades e desafios. Belo Horizonte: Editora UFMG, 2011. v. 1, p. 27-50.

RUBIM, Antonio Albino Canelas. Dos sentidos do marketing cultural: pré textos em 08/12/1997. Disponível em: http://www.cdp.ufpr.br/ucap/anexos/organizacao de eventos/parte01/textos marketing cultural/dos sentidos do marketing cultural.pd f. Acesso em: 10 out. 2012.

THOMPSON, E. P. A miséria da teoria ou um planetário de erros. Rio de Janeiro: Zahar, 1981.

THOMPSON, E. P. A formação da classe operária inglesa. Rio de Janeiro: Paz e Terra, 1987.

WILLIAMS, Raymond. Palavras-Chave: um vocabulário de cultura e sociedade. São Paulo: Boitempo, 2007.

\section{Endereço da Autora:}

Nadia Bueno Rezende

Universidade Federal de Minas Gerais

Escola de Educação Física, Fisioterapia e Terapia Ocupacional

Programa de Pós-Graduação Interdisciplinar em Estudos do Lazer

Av. Antonio Carlos 6627 - Campus UFMG - Pampulha.

Belo Horizonte, Minas Gerais. CEP. 31.270-901

Endereço eletrônico: nadiaef@hotmail.com 